\title{
Immediate Direct Peripheral Vasoconstriction in Response to Hyperinsulinemia and Metformin in the Anesthetized Pig
}

\author{
F. MARKOS ${ }^{1}$, C. M. SHORTT ${ }^{1}$, D. EDGE ${ }^{1}$, T. RUANE-O'HORA ${ }^{1}$, M. I. M. NOBLE ${ }^{2}$ \\ ${ }^{1}$ Department of Physiology, University College Cork, Cork, Ireland, ${ }^{2}$ Cardiovascular Medicine, \\ University of Aberdeen, Scotland, UK
}

Received January 15, 2014

Accepted March 13, 2014

On-line June 5, 2014

\begin{abstract}
Summary
Elevated levels of insulin have been reported to induce both an arterial vasodilation mediated by nitric oxide (NO), and vasoconstriction mediated by endothelin and reactive oxygen radicals. Metformin, used to control blood glucose levels in type 2 diabetes, has also been shown to cause NO-mediated dilation of conduit arteries. It is possible that these contradictory vascular effects are due to a non-direct action on arteries. Therefore, the direct effect of high levels of insulin and metformin infusion on resistance artery diameter was evaluated. Experiments were carried out on the anesthetized pig; blood flow and pressure were measured in the iliac artery. An adjustable snare was applied to the iliac above the pressure and flow measurement site to induce step decreases (3-4 occlusions at 5 min intervals were performed for each infusion) in blood flow, and hence iliac pressure, and the conductance ( $\Delta$ flow / $\Delta$ pressure) calculated. Saline, insulin (20 and $40 \mathrm{mUSP} / \mathrm{l} / \mathrm{min}$ ), and metformin $(1 \mu \mathrm{g} / \mathrm{ml} / \mathrm{min})$ were infused separately downstream of the adjustable snare and their effect on arterial conductance assessed. Insulin at both infusion rates and metformin caused a significant reduction in peripheral vascular conductance. In conclusion, hyperinsulinemia and metformin infusion constrict resistance arterial vessels in vivo.
\end{abstract}

\section{Key words}

Metformin • Insulin • Type 2 diabetes • Vascular resistance

\section{Corresponding author}

F. Markos, Department of Physiology, University College Cork, Cork, Ireland. E-mail: f.markos@ucc.ie

\section{Introduction}

The increase in the population of a group of conditions, insulin resistance, metabolic syndrome and type 2 diabetes mellitus associated with hypertension has focused attention on the effects of insulin and metformin upon blood vessels (Hardman et al. 1992, Dubrey et al. 1994, Stubbs et al. 1999a, b, Mather et al. 2001, Davis et al. 2006). It has been shown that insulin causes nitric oxide (NO) mediated vascular smooth muscle relaxation of the pig iliac, a conduit artery (Ruane-O'Hora et al. 2011, 2012). Hyperinsulinemia has also been shown to cause dilation of forearm vessels (Hermann et al. 2004), indicating a relaxation of resistance vessels, in addition insulin stimulates NO production from isolated umbilical vein endothelial cells (Zeng et al. 2000). However, insulin also releases endothelin and reactive oxygen species which are both vasoconstrictors (Ferri et al. 1995, Cardillo et al. 1999, Potenza et al. 2009). In fact, there are a number of published studies on peripheral resistance vessels that are not compatible with a dilatory effect of insulin (Sobrevia et al. 1998, Westerbacka et al. 2001, Westerbacka and Yki-Jarvinen 2002, Hansen et al. 2004, Jansson 2007, Kearney et al. 2008, Potenza et al. 2009). More difficult to interpret are the effects of insulin in addition to adrenaline or acetylcholine application (McNally et al. 1995, Mayhan et al. 2001), or contraction in response to electrical field stimulation (Garcia-Villalon et al. 2000) and inhibition of contraction by insulinstimulated glucose transport (Kahn et al. 1995, Kahn and Song 1995).

It is possible that the contrary results in the literature on the effect of insulin on arterial diameter 
could be due to duration of exposure; specifically, indirect effects that could take place over longer time durations compared with acute exposure, as used in the iliac artery experiments (Ruane-O'Hora et al. 2011, 2012, 2013a, b). In the present study we set out to test this hypothesis by making direct acute exposures of the porcine iliac peripheral vascular bed to porcine insulin as well as metformin, which is the mainstay of treatment in type 2 diabetes, and has also been shown to cause NOmediated dilation of the iliac artery (Davis et al. 2006, Ruane-O'Hora et al. 2012).

\section{Methods}

This investigation was carried out under licenses issued by the Department of Health Ireland as directed by the Cruelty to Animals Act Ireland and European Union and International Statutory Instructions.

\section{Surgery and instrumentation}

Ten female landrace pigs $(20-25 \mathrm{~kg})$ were sedated with ketamine $(14 \mathrm{mg} / \mathrm{kg})$ and xylazine $(2.7 \mathrm{mg} / \mathrm{kg})$ i.m., not all ten were subjected to all the interventions, the half-life of ketamine is 10-15 min and so the dose used for sedation would not affect the measured physiological parameters. A cannula was inserted into an ear vein and the animal was anesthetized with a bolus, followed by a continuous infusion of sodium pentobarbital (induction $30 \mathrm{mg} / \mathrm{kg}$; maintenance $6 \mathrm{mg} / \mathrm{kg} / \mathrm{h}$ i.v.). The continuous infusion was maintained via a catheter inserted into the jugular vein, using an infusion pump (Harvard). End-tidal carbon dioxide $\left(\mathrm{ETCO}_{2}\right)$, pulse oximetry and core temperature were monitored using SurgiVet AdvisorVital Signs Monitor (Smiths Medical, Dublin, $\mathrm{OH}$ ). Arterial $\mathrm{pH}, \mathrm{PCO}_{2}$ and $\mathrm{PO}_{2}$ were assessed using a hand held i-STAT blood gas analyzer (Abbot Point of Care Inc, Princeton, NJ) and maintained within their normal ranges. Blood glucose was monitored with a Bayer Glucometer. Following tracheotomy animals were ventilated with $40 \% \mathrm{O}_{2}$ in room air using a Harvard ventilation pump at a rate adjusted to keep end-tidal and arterial $\mathrm{PCO}_{2}$ within a normal range. A cannula attached to a pressure transducer (Grass; Grass Technologies, West Warwick, RI) was inserted into the left carotid artery for measurement of arterial blood pressure. The iliac artery was prepared as previously described (Kelly et al. 2006). Briefly, the left or right iliac artery was dissected from the aortic bifurcation to the deep femoral branch, and a cannula attached to a 3-way tap was inserted into the deep femoral artery for infusions of saline, insulin, or metformin downstream of the flow and pressure measurement sites in the iliac. During certain experiments, ultrasonic piezoelectric crystals were placed on diametrically opposite sides of the iliac artery for continuous measurement of the diameter using a sonomicrometer (Sonometrics Corporation, London, Ontario, Canada). An ultra-sonic transit time flow transducer (Transonic Systems Inc, Ithaca, New York, NY) was placed around the artery to measure blood flow. Pressure within the iliac was measured with a second catheter tipped manometer (Millar, Houston, USA) placed in a side branch of the iliac. An adjustable snare was placed just below the iliac-aorta bifurcation, above the pressure and flow measurement sites, to produce controlled restrictions to blood flow. Hemodynamic signals were recorded using Power lab pre-amplifiers and software (AD Instruments Ltd, Oxford, UK) and a Dell computer. Electronic measurements of hemodynamic variables were taken off-line using Chart 7 software (AD Instruments). Following experimental procedures, animals were killed using a lethal intravenous injection of pentobarbitone and $\mathrm{KCl}$.

\section{Experimental procedure}

Following instrumentation, all variables inscribed on the electronic display of the Powerlab system were monitored until they remained constant. This steady state was maintained for half an hour before proceeding with the following interventions.

The proximal snare was used to restrict blood flow 3-4 times control levels as recently described (Ruane-O'Hora et al. 2013a,b). Close intra-arterial infusions via the deep femoral artery were made of: (a) saline at the same flow rate as the insulin solution infusion rates, (b) insulin at an infusion at a rate of 20 or $40 \mathrm{mUSP} / \mathrm{l} / \mathrm{min}$, (c) metformin at an infusion rate of $1 \mu \mathrm{g} / \mathrm{ml} / \mathrm{min}$. The infused concentrations of insulin and metformin were chosen because they cause NO mediated dilatation of the iliac conduit artery (O'Hora et al. 2012). For each infusion, changes in flow and arterial pressure were observed in the absence of any occlusion of the test segment below the snare. Then, while continuing the infusion for 4-5 $\mathrm{min}$, the occluders were tightened in distinct steps of restriction of blood flow and flow and test segment pressure recorded. 


\section{Measurements and statistical analysis}

Chart records were analyzed off line in accordance with accepted principles (Braakman et al. 1983). Group values were expressed as mean \pm S.E.M. The instantaneous peripheral vascular conductance was assessed for individual step changes at each step as the immediate drop flow $(\Delta \mathrm{F})$, divided by the instantaneous drop in pressure $(\Delta \mathrm{P})$. In the data illustrated in Figure 2, the lines connect the saline to the intervention values in each pig and were normally distributed and analyzed by paired t test. The slopes were subjected to homogeneity of regressions analysis (SPSS). The $\mathrm{F}$ variance ratios were calculated for differences in slopes (Drake-Holland et al. 1984).

All data were tested for normal distribution. Normally distributed data were subjected to unpaired or paired Student's t test as appropriate. Non-normally distributed data were subjected to Mann Whitney or Wilcoxon paired sign test, or paired chi square (with correction for continuity) as appropriate. Comparison of linear regression data were carried out by ANCOVA.

\section{Results}

\section{Insulin}

Infusion of saline or insulin was carried out during step decreases in blood flow and test segment pressure, as described recently (Ruane-O'Hora et al. $2013 \mathrm{a}, \mathrm{b})$. The recovery of flow and test segment pressure from the initial value after the step was due to autoregulation and was seen in both saline and insulin infusion runs.

In order to enumerate the change in peripheral vascular conductance more precisely, the linear regression lines for the change in flow versus the change in diameter for the experiments in which saline or the same infusion rate to achieve delivery of 20 and 40 $\mathrm{mUSP} / 1 / \mathrm{min}$ insulin in blood (Fig. 1). Both infusion rates of insulin, 40 and $20 \mathrm{mUSP} / \mathrm{l} / \mathrm{min}$, caused a significant decrease in conductance, the saline slope for the lower infusion rate (Fig. 1A) fell from $1.69 \pm 0.16$ (slope \pm s.e. slope $)$ to $1.27 \pm 0.43 \mathrm{ml} / \mathrm{min} / \mathrm{mm} \mathrm{Hg} \quad(\mathrm{P}<0.00001$, homogeneity of slopes test); the saline slope for the insulin $40 \mathrm{mUSP} / \mathrm{l} / \mathrm{min}$ was $1.58 \pm 0.17$ and this fell to $0.67 \pm 0.32 \mathrm{ml} / \mathrm{min} / \mathrm{mm} \mathrm{Hg}(\mathrm{P}<0.00001$, homogeneity of slopes test). There was no significant difference between the slopes of the insulin infusion $(\mathrm{P}=0.514$, homogeneity of slopes test).
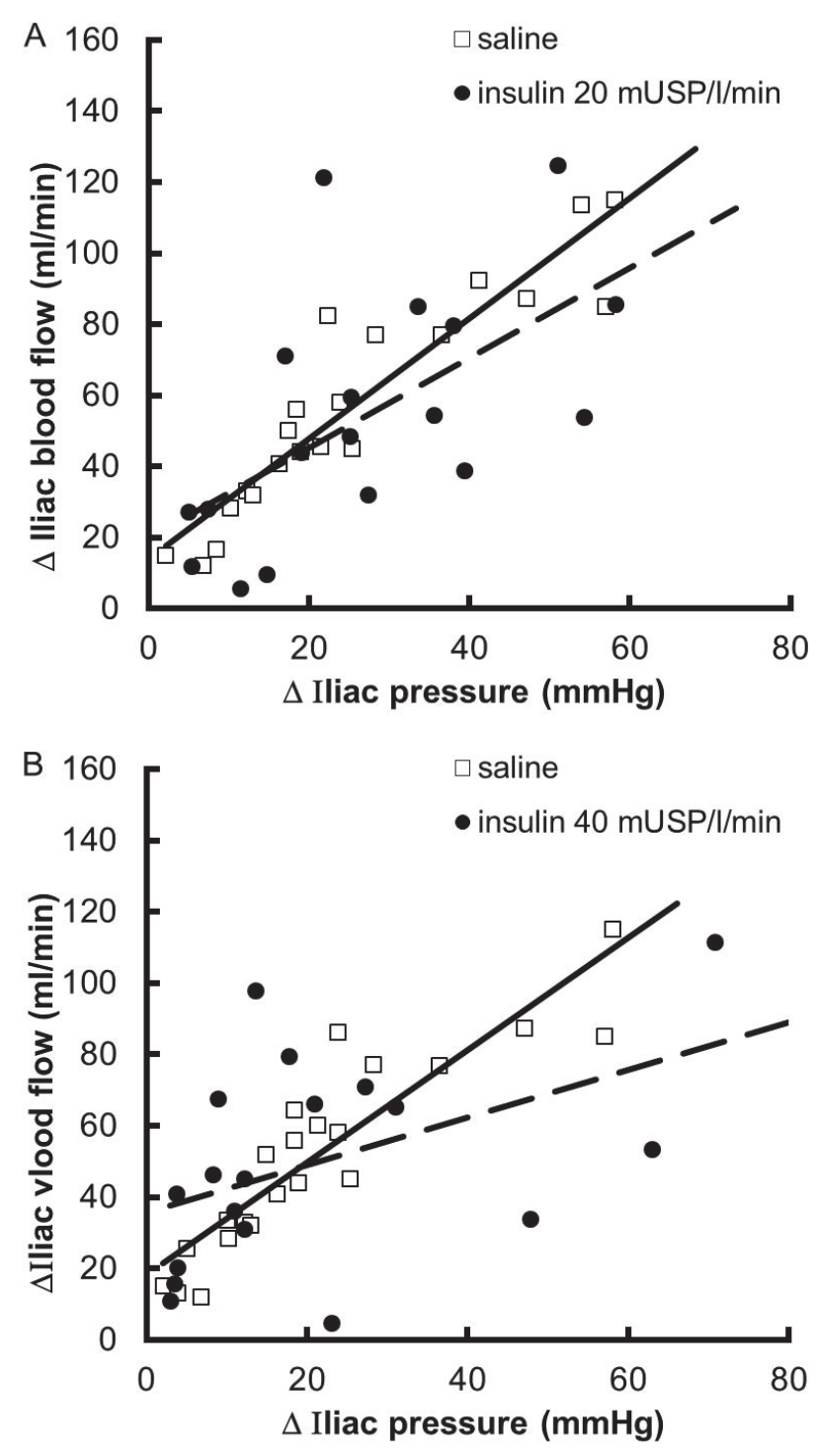

Fig. 1. The effect of insulin infusion on arterial conductance. Insulin infusion at $20 \mathrm{mUSP} / \mathrm{l} / \mathrm{min}(\mathbf{A} ; \mathrm{n}=6$; dashed line) and $40 \mathrm{mUSP} / \mathrm{l} / \mathrm{min}(\mathbf{B} ; \mathrm{n}=6$, dashed line) both caused a significant decrease $(P<0.0001$, test homogeneity of slope) in arterial conductance when compared to saline infusion (solid line).

\section{Metformin}

The recovery of flow and test segment pressure from the initial value after the step was due to autoregulation and was seen in both saline and metformin infusion runs. Exposure of the iliac peripheral vasculature to $1 \mu \mathrm{g} / \mathrm{ml} / \mathrm{min}$ compared with saline controls resulted in the values presented in Figure 2. The mean peripheral vascular conductance decreased with metformin from $2.38 \pm 0.15$ control to $1.72 \pm 0.17 \mathrm{ml} / \mathrm{min} / \mathrm{mm} \mathrm{Hg}(\mathrm{P}=0.001$, paired $\mathrm{t}$ test). Metformin infusion caused significant decreased conductance, i.e. an increase in vascular resistance, the saline slope fell from $1.69 \pm 0.16$ (slope \pm s.e. slope $)$ to $1.25 \pm 0.3 \mathrm{ml} / \mathrm{min} / \mathrm{mm} \mathrm{Hg} \quad(\mathrm{P}<0.00001$, homogeneity of slopes test). 


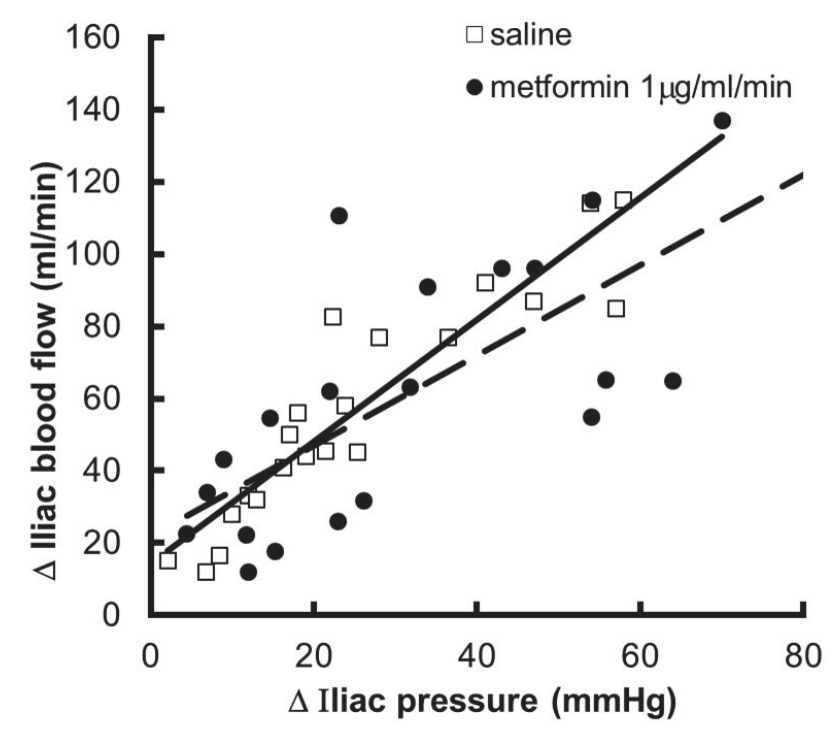

Fig. 2. The effect of metformin infusion on arterial conductance. Metformin infusion at $1 \mu \mathrm{g} / \mathrm{ml} / \mathrm{min}(\mathrm{n}=6$, dashed line) caused a significant decrease $(P<0.0001$, test homogeneity of slope) in arterial conductance when compared to saline infusion (solid line).

\section{Discussion}

Insulin

We previously examined the direct effect of applying raised insulin doses to the endothelial luminal surface of the pig iliac artery, and recorded a NO dependent dilatation (Ruane-O'Hora et al. 2011, 2012). The results were compatible with those from unanesthetized human studies, because our experiments could be influenced by species variation and the effects of sedation and anesthesia, as could the other animal studies referenced. There were no other studies available on the effects of insulin on conduit artery, but there was considerable published data on the effect of insulin on resistance vessels. Insulin is thought to be a NO dependent dilator of resistance vessels (Steinberg et al. 1994, Muniyappa et al. 2007) and to increase NO synthase (Kawaguchi et al. 2001). This effect was thought to be indirect, since it was claimed to occur when insulin is administered systemically, but not following direct arterial injection (Cardillo et al. 1998). The absence of a direct effect of insulin on peripheral resistance was accompanied by mechanistic data showing an increase in endothelin-1, leading to vasoconstriction (Cardillo et al. 1999, Muniyappa et al. 2007) and data showing activation of the sympathetic nervous system (Muniyappa et al. 2007). In order to exclude indirect effects of systemic hyperinsulinemia (Baron 1994), in the present study a method involving step changes in pressure and flow into the peripheral iliac vascular bed was used (Ruane-O'Hora et al. 2013a, b).

Interest in the effect of insulin resistance associated with high insulin levels in patients with acute coronary syndromes (Stubbs et al. 1999a, b) was rearoused by the findings that the effect of insulin on vascular endothelium is impaired in insulin resistant subjects (Sobrevia et al. 1998, Jansson 2007, Kearney et al. 2008, Potenza et al. 2009). The effect of insulin on arterial stiffness is also impaired in insulin resistant subjects (Westerbacka et al. 2001, Westerbacka and YkiJarvinen 2002, Hansen et al. 2004). These effects were clearly contrary to our findings of NO dependent smooth muscle relaxation in conduit artery wall (Ruane-O'Hora et al. 2011, 2012), and led to the hypothesis that there was a direct dilatory effect of insulin on peripheral resistance vessels, and that the contrary effects in the literature were secondary, occurring over a longer time span.

The results of the present study clearly disprove this hypothesis, since the direct acute effect of insulin upon peripheral vascular conductance actually found was one of vasoconstriction, not the expected vasodilatation. There is a clear separation of the data for changes in flow during step changes in pressure in the negative direction. The results of the insulin infusions suggest that there may be a positive concentration-response relationship, but full delineation of this would require a very large number of experiments, which were beyond our resources.

This leads us to conclude that the dilatory effects of insulin on peripheral resistance vessels previously found by Cardillo et al. (1998, 1999) were correctly concluded by those authors to be indirect. Their failure to detect a direct constrictor effect could be attributed to the lesser accuracy of measurement possible in human subjects, compared to an invasive animal method. The results also seem compatible with the conclusions indicating that high insulin concentrations in insulin resistance subjects cause a constricting effect upon the vasculature (Cardillo et al. 1999, Potenza et al. 2009). In addition to a possible contribution to increased arterial stiffness and hypertension found in such patients; no doubt there are other contributing factors to this hypertension. Our results are also compatible with the insulin-induced vasoconstriction associated with protein kinase C activation (Bakker et al. 2008). In isolated cerebral vessels, an initial vasoconstriction was seen, followed by vasodilation (Katakam et al. 2009), 
suggesting compatibility with our observations of initial responses only; the vasoconstriction in these experiments was abolished by removal of reactive oxygen species. When insulin-mediated vasorelaxation is the dominant response, as in isolated aortic rings, the relaxation is enhanced by endothelin antagonism (Elgebaly et al. 2008). It is claimed that endothelin ET-1 and ETA receptors are activated by hyperglycemia and alter vascular structure in Type 2 diabetes (Sachidanandam et al. 2009).

There are clear associations between diabetes mellitus and hypertension, a condition of high peripheral resistance (Sowers 2013) and between diabetes mellitus and endothelial dysfunction (Cosentino and Luscher 1998). Of particular concern is the prevalence of insulin resistance (Park et al. 2005), a predictor of future diabetes mellitus in young subjects identified this as a cardiovascular risk in young Finnish subjects (Park et al. 2005). The "SEARCH" for diabetes in youth is a multicentre study of the prevalence of this condition from early reports (SEARCH for Diabetes in Youth Study Group 2006, Writing Group for the SEARCH for Diabetes in Youth Study Group 2007). Of particular relevance to our present interest is the endothelial dysfunction found in insulin resistance (Kearney et al. 2008) and the concept of endothelial insulin resistance (Kanter and Bornfeldt 2013).

\section{Metformin}

This drug is accepted by many as first line treatment in diabetes mellitus which is not insulin dependent (Type 2) (United Kingdom Prospective Diabetes Study 1995, Holman 2007) and is resistant to dietary control (Brehm et al. 2003, Samaha et al. 2003). It is widely recommended as having a hypoglycemic action, a beneficial effect on endothelial dysfunction (Mather et al. 2001) and to induce reversal of insulin resistance (Verma et al. 2000, Wiernsperger 2000, Clarke et al. 2005). The drug is not thought to affect blood pressure (Wulffele et al. 2004). Most relevant to the present study is the finding of improved peripheral vascular flow (Sirtori et al. 1984) over longer duration of metformin exposure than our experimental period (20 min). Nevertheless we postulated that we would find a peripheral vasodilatation within $20 \mathrm{~min}$ but this was disproved in the present series of experiments.

There are few accounts of metformin inducing increased vascular resistance deleted, in accordance with our present findings. The main mechanism claimed for the effect of metformin on vascular function, is activation of AMP-activated protein kinase. However, this would not explain a short term vasoconstrictive effect, for which no mechanism has appeared in the literature. It is possible that our observations have been missed in existing studies, in which the duration of metformin application is much longer than in our experiments.

\section{Conclusions}

It would appear from our results in vivo, that the vasoconstrictor effects of insulin upon peripheral resistance, attributed to endothelin and reactive oxygen species, out-weigh the vasodilator effect attributed to NO production. The finding of short term vasoconstriction in response to metformin infusion appears to be at variance with all other reports of the effects of metformin on the vasculature. Both these findings were unexpected, as our previous studies on conduit artery revealed NO-mediated dilatation with both agents!

\section{Conflict of Interest}

There is no conflict of interest.

\section{Acknowledgements}

SurgiVet Monitor purchased with a grant from the Strategic Research Fund UCC 2012.

\section{References}

BAKKER W, SIPKEMA P, STEHOUWER CD, SERNE EH, SMULDERS YM, VAN HINSBERGH VW, ERINGA EC: Protein kinase $\mathrm{C}$ theta activation induces insulin-mediated constriction of muscle resistance arteries. Diabetes 57: 706-713, 2008.

BARON AD: Hemodynamic actions of insulin Am J Physiol 267: E187-E202, 1994.

BRAAKMAN R, SIPKEMA P, WESTERHOF N: Steady state and instantaneous pressure-flow relationships: characterisation of the canine abdominal periphery. Cardiovasc Res 17: 577-588, 1983. 
BREHM BJ, SEELEY RJ, DANIELS SR, D'ALESSIO DA: A randomized trial comparing a very low carbohydrate diet and a calorie-restricted low fat diet on body weight and cardiovascular risk factors in healthy women. $J$ Clin Endocrinol Metab 88: 1617-1623, 2003.

CARDILLO C, KILCOYNE CM, NAMBI SS, CANNON RO, QUON MJ, PANZA JA: Vasodilator response to systemic but not to local hyperinsulinemia in the human forearm. Hypertension 32: 740-745, 1998.

CARDILLO C, NAMBI S, KILCOYNE CM, CHOUCAIR WK, KATZ A, QUON MJ, PANZA JA: Insulin stimulates both endothelin and nitric oxide activity in the human forearm. Circulation 100: 820-825, 1999.

CLARKE PM, GRAY AM, BRIGGS A, STEVENS RJ, MATTHEWS DR, HOLMAN RR; UNITED KINGDOM PROSPECTIVE DIABETES STUDY (UKPDS): Cost-utility analyses of intensive blood glucose and tight blood pressure control in type 2 diabetes (UKPDS 72). Diabetologia 48: 868-877, 2005.

COSENTINO F, LUSCHER TF: Endothelial dysfunction in diabetes mellitus. J Cardiovasc Pharmacol 32 (Suppl 3): S54-S61, 1998.

DAVIS BJ, XIE Z, VIOLLET B, ZOU MH: Activation of the AMP-activated kinase by antidiabetes drug metformin stimulates nitric oxide synthesis in vivo by promoting the association of heat shock protein 90 and endothelial nitric oxide synthase. Diabetes 55: 496-505, 2006.

DRAKE-HOLLAND AJ, LAIRD JD, NOBLE MI, SPAAN JA, VERGROESEN I: Oxygen and coronary vascular resistance during autoregulation and metabolic vasodilation in the dog. J Physiol 348: 285-299, 1984.

DUBREY SW, REAVELEY DR, SEED M, LANE DA, IRELAND H, O'DONNELL M, O'CONNOR B, NOBLE MI, LESLIE RD: Risk factors for cardiovascular disease in IDDM. A study of identical twins. Diabetes 43: 831835, 1994.

ELGEBALY MM, KELLY A, HARRIS AK, ELEWA H, PORTIK-DOBOS V, KETSAWATSOMKRON P, MARRERO M, ERGUL A: Impaired insulin-mediated vasorelaxation in a nonobese model of type 2 diabetes: role of endothelin-1. Can J Physiol Pharmacol 86: 358-364, 2008.

FERRI C, CARLOMAGNO A, COASSIN S, BALDONCINI R, CASSONE FALDETTA MR, LAURENTI O, PROPERZI G, SANTUCCI A, DE MATTIA G: Circulating endothelin-1 levels increase during euglycemic hyperinsulinemic clamp in lean NIDDM men. Diabetes Care 18: 226-233, 1995.

GARCIA-VILLALON AL, FERNANDEZ N, MONGE L, MARTINEZ MA, GOMEZ B, DIEGUEZ G: Insulin effects on the sympathetic contraction of rabbit ear arteries. Gen Pharmacol 34: 221-226, 2000.

HANSEN TW, JEPPESEN J, RASMUSSEN S, IBSEN H, TORP-PEDERSEN C: Relation between insulin and aortic stiffness: a population-based study. J Hum Hypertens 18: 1-7, 2004.

HARDMAN TC, DUBREY SW, LESLIE DG, HAFIZ M, NOBLE MI, LANT AF: Erythrocyte sodium-lithium countertransport and blood pressure in identical twin pairs discordant for insulin dependent diabetes. BMJ 305: 215-219, 1992.

HERMANN TS, IHLEMANN N, DOMINGUEZ H, RASK-MADSEN C, KOBER L, TORP-PEDERSEN C: Prolonged local forearm hyperinsulinemia induces sustained enhancement of nitric oxide-dependent vasodilation in healthy subjects. Endothelium 11: 231-239, 2004.

HOLMAN R: Metformin as first choice in oral diabetes treatment: the UKPDS experience. Journ Annu Diabetol Hotel Dieu: 13-20, 2007.

JANSSON PA: Endothelial dysfunction in insulin resistance and type 2 diabetes. J Intern Med 262: 173-183, 2007.

KAHN AM, SONG T: Insulin inhibits dog vascular smooth muscle contraction and lowers $\mathrm{Ca}^{2+}{ }_{\mathrm{i}}$ by inhibiting $\mathrm{Ca}^{2+}$ influx. J Nutr 125: 1732S-1737S, 1995.

KAHN AM, LICHTENBERG RA, ALLEN JC, SEIDEL CL, SONG T: Insulin-stimulated glucose transport inhibits $\mathrm{Ca}^{2+}$ influx and contraction in vascular smooth muscle. Circulation 92: 1597-1603, 1995.

KANTER JE, BORNFELDT KE: Evidence stacks up that endothelial insulin resistance is a culprit in atherosclerosis. Circ Res 113: 352-354, 2013.

KATAKAM PV, DOMOKI F, LENTI L, GASPAR T, INSTITORIS A, SNIPES JA, BUSIJA DW: Cerebrovascular responses to insulin in rats. J Cereb Blood Flow Metab 29: 1955-1967, 2009.

KAWAGUCHI M, KOSHIMURA K, SOHMIYA M, MURAKAMI Y, GONDA T, KATO Y: Effect of insulin on nitric oxide synthase-like immunostaining of arteries in various organs in Zucker diabetic fatty rats. Eur $J$ Endocrinol 145: 343-349, 2001. 
KEARNEY MT, DUNCAN ER, KAHN M, WHEATCROFT SB: Insulin resistance and endothelial cell dysfunction: studies in mammalian models. Exp Physiol 93: 158-163, 2008.

KELLY R, RUANE-O'HORA T, NOBLE MI, DRAKE-HOLLAND AJ, SNOW HM: Differential inhibition by hyperglycaemia of shear stress- but not acetylcholine-mediated dilatation in the iliac artery of the anaesthetized pig. J Physiol 573: 133-145, 2006.

MATHER KJ, VERMA S, ANDERSON TJ: Improved endothelial function with metformin in type 2 diabetes mellitus. J Am Coll Cardiol 37: 1344-1350, 2001.

MAYHAN WG, TRAUERNICHT AK, IRVINE SD: Insulin reverses impaired acetylcholine-induced dilatation of the rat basilar artery during diabetes mellitus. Brain Res 893: 195-201, 2001.

MCNALLY PG, LAWRENCE IG, WATT PA, HILLIER C, BURDEN AC, THURSTON H: The effect of insulin on the vascular reactivity of isolated resistance arteries taken from healthy volunteers. Diabetologia 38: 467-473, 1995.

MUNIYAPPA R, MONTAGNANI M, KOH KK, QUON MJ: Cardiovascular actions of insulin. Endocr Rev 28: 463491, 2007.

PARK SH, LEE WY, RHEE EJ, JEON WK, KIM BI, RYU SH, KIM SW: Relative risks of the metabolic syndrome according to the degree of insulin resistance in apparently healthy Korean adults. Clin Sci (Lond) 108: 553$559,2005$.

POTENZA MA, ADDABBO F, MONTAGNANI M: Vascular actions of insulin with implications for endothelial dysfunction. Am J Physiol 297: E568-E577, 2009.

RUANE-O'HORA T, MARKOS F, WAINWRIGHT C, AL-OBAIDI M, NOBLE MIM: The responses of the iliac artery to insulin: direct delayed nitric oxide-mediated dilatation. Br J Diabetes Vasc Dis 11: 130-136, 2011.

RUANE-O’HORA T, MARKOS F, WIERNSPERGER NF, NOBLE MI: Metformin causes nitric oxide-mediated dilatation in a shorter time than insulin in the iliac artery of the anesthetized pig. J Cardiovasc Pharmacol 59: 182-187, 2012.

RUANE-O'HORA T, EDGE D, SHORTT CM, MARKOS F, NOBLE MI: Responses of iliac conduit artery and hindlimb resistance vessels to luminal hyperfructosemia in the anaesthetized pig. Acta Physiol (Oxf) 209: 254261, 2013a.

RUANE-O'HORA T, SHORTT CM, EDGE D, MARKOS F, NOBLE MI: Intraluminal hyperglycaemia causes conduit and resistance artery dilatation and inhibits vascular autoregulation in the anaesthetised pig. Can J Physiol Pharmacol 91: 1031-1036, 2013b.

SACHIDANANDAM K, HUTCHINSON JR, ELGEBALY MM, MEZZETTI EM, DORRANCE AM, MOTAMED K, ERGUL A: Glycemic control prevents microvascular remodeling and increased tone in type 2 diabetes: link to endothelin-1. Am J Physiol 296: R952-R959, 2009.

SAMAHA FF, IQBAL N, SESHADRI P, CHICANO KL, DAILY DA, MCGRORY J, WILLIAMS T, WILLIAMS M, GRACELY EJ, STERN L: A low-carbohydrate as compared with a low-fat diet in severe obesity. $N$ Engl J Med 348: 2074-2081, 2003.

SEARCH FOR DIABETES IN YOUTH STUDY GROUP, LIESE AD, D'AGOSTINO RB Jr, HAMMAN RF, KILGO PD, LAWRENCE JM, LIU LL, LOOTS B, LINDER B, MARCOVINA S, RODRIGUEZ B, STANDIFORD D, WILLIAMS DE: The burden of diabetes mellitus among US youth: prevalence estimates from the SEARCH for Diabetes in Youth Study. Pediatrics 118: 1510-1518, 2006.

SIRTORI CR, FRANCESCHINI G, GIANFRANCESCHI G, SIRTORI M, MONTANARI G, BOSISIO E, MANTERO E, BONDIOLI A: Metformin improves peripheral vascular flow in nonhyperlipidemic patients with arterial disease. J Cardiovasc Pharmacol 6: 914-923, 1984.

SOBREVIA L, YUDILEVICH DL, MANN GE: Elevated D-glucose induces insulin insensitivity in human umbilical endothelial cells isolated from gestational diabetic pregnancies. $J$ Physiol 506: 219-230, 1998.

SOWERS JR: Diabetes mellitus and vascular disease. Hypertension 61: 943-947, 2013.

STEINBERG HO, BRECHTEL G, JOHNSON A, FINEBERG N, BARON AD: Insulin-mediated skeletal muscle vasodilation is nitric oxide dependent. A novel action of insulin to increase nitric oxide release. J Clin Invest 94: 1172-1179, 1994. 
STUBBS PJ, ALAGHBAND-ZADEH J, LAYCOCK JF, COLLINSON PO, CARTER GD, NOBLE MI: Significance of an index of insulin resistance on admission in non-diabetic patients with acute coronary syndromes. Heart 82: 443-447, 1999a.

STUBBS PJ, LAYCOCK J, ALAGHBAND-ZADEH J, CARTER G, NOBLE MI: Circulating stress hormone and insulin concentrations in acute coronary syndromes: identification of insulin resistance on admission. Clin Sci (Lond) 96: 589-595, $1999 \mathrm{~b}$.

UNITED KINGDOM PROSPECTIVE DIABETES STUDY (UKPDS) 13: Relative efficacy of randomly allocated diet, sulphonylurea, insulin, or metformin in patients with newly diagnosed non-insulin dependent diabetes followed for three years BMJ 310: 83-88, 1995.

VERMA S, YAO L, DUMONT AS, MCNEILL JH: Metformin treatment corrects vascular insulin resistance in hypertension. J Hypertens 18: 1445-1450, 2000.

WESTERBACKA J, YKI-JARVINEN H: Arterial stiffness and insulin resistance. Semin Vasc Med 2: 157-164, 2002.

WESTERBACKA J, SEPPALA-LINDROOS A, YKI-JARVINEN H: Resistance to acute insulin induced decreases in large artery stiffness accompanies the insulin resistance syndrome. J Clin Endocrinol Metab 86: 5262-5268, 2001.

WIERNSPERGER NF: Metformin: intrinsic vasculoprotective properties. Diabetes Technol Ther 2: 259-272, 2000.

WRITING GROUP FOR THE SEARCH FOR DIABETES IN YOUTH STUDY GROUP, DABELEA D, BELL RA, D'AGOSTINO RB Jr, IMPERATORE G, JOHANSEN JM, LINDER B, LIU LL, LOOTS B, MARCOVINA S, MAYER-DAVIS EJ, PETTITT DJ, WAITZFELDER B: Incidence of diabetes in youth in the United States. JAMA 297: 2716-2724, 2007.

WULFFELE MG, KOOY A, DE ZEEUW D, STEHOUWER CD, GANSEVOORT RT: The effect of metformin on blood pressure, plasma cholesterol and triglycerides in type 2 diabetes mellitus: a systematic review. J Intern Med 256: 1-14, 2004.

ZENG G, NYSTROM FH, RAVICHANDRAN LV, CONG LN, KIRBY M, MOSTOWSKI H, QUON MJ: Roles for insulin receptor, PI3-kinase, and Akt in insulin-signaling pathways related to production of nitric oxide in human vascular endothelial cells. Circulation 101: 1539-1545, 2000. 